\title{
The Impact of Carbonate on Surface Protonation, Electron Transfer and Crystallization Reactions in Iron Oxide Nanoparticles and Colloids DE-FG02-07ER15840
}

\author{
Final Report, David A. Dixon, The University of Alabama
}

This project addresses key issues of importance in the geochemical behavior of iron oxides and in the geochemical cycling of carbon and iron. For Fe, we are specifically studying the influence of carbonate on electron transfer reactions, solid phase transformations, and the binding of carbonate to reactive sites on the edges of particles. The emphasis on carbonate arises because it is widely present in the natural environment, is known to bind strongly to oxide surfaces, is reactive on the time scales of interest, and has a speciation driven by acid-base reactions. The geochemical behavior of carbonate strongly influences global climate change and $\mathrm{CO}_{2}$ sequestration technologies. Our goal is to answer key questions with regards to specific site binding, electron transfer reactions, and crystallization reactions of iron oxides that impact both the geochemical cycling of iron and $\mathrm{CO}_{2}$ species. Our work is focused on the molecular level description of carbonate chemistry in solution including the prediction of isotope fractionation factors. We have also done work on critical atmospheric species.

\section{Isotope fractionation factors}

${ }^{12,13} \mathrm{C}$ isotopic fractionation factors. ${ }^{12,13} \mathrm{C}$ isotopic fractionation between gaseous $\mathrm{CO}_{2}(\mathrm{~g})$, the aqueous carbonate species $\left[\mathrm{CO}_{2}(\mathrm{aq}), \mathrm{HCO}_{3}{ }^{-}(\mathrm{aq}), \mathrm{CO}_{3}{ }^{2-}(\mathrm{aq})\right]$, and the common carbonate minerals (calcite, dolomite, and aragonite) is fundamental to understanding a variety of geochemical processes involving the carbon cycle. Several studies have reported measurements of carbonisotope fractionation among species in the aqueous $\mathrm{CO}_{2}$ system. It is well established that, at equilibrium, $\mathrm{CO}_{2}(\mathrm{aq})$ is isotopically lighter than $\mathrm{CO}_{2}(\mathrm{~g})$ by about 1 part per thousand (per mil) and that the dissolved ionic species $\mathrm{HCO}_{3}{ }^{-}(\mathrm{aq})$ and $\mathrm{CO}_{3}{ }^{2-}(\mathrm{aq})$ are both isotopically heavier than $\mathrm{CO}_{2}(\mathrm{~g})$. Historically, there has been some disagreement about the extent of fractionation of the aqueous ionic species relative to the gas but recent work suggests that $\mathrm{HCO}_{3}{ }^{-}(\mathrm{aq})$ is enriched in ${ }^{13} \mathrm{C}$ by 7.9 per mil and that $\mathrm{CO}_{3}^{-}(\mathrm{aq})$ is enriched in ${ }^{13} \mathrm{C}$ by 5.9 per mil relative to $\mathrm{CO}_{2}(\mathrm{~g})$ at $25^{\circ} \mathrm{C}$. The difficulties of making accurate isotopic measurements on aqueous systems with dynamic chemical speciation with carbonate led us to use computational chemistry approaches to further interpret the experimental measurements.

Because of the broad geochemical significance of the carbon cycle, controlled, in part, by aqueous carbonate species and carbonate minerals, we have assessed the performance of electronic structure methods for predicting carbon-isotope fractionation in the aqueous carbonate system. Our approach is to extend computational chemical methods at the molecular orbital (MO) theory and density functional theory (DFT) levels for the prediction of carbon-isotope fractionation between $\mathrm{CO}_{2}(\mathrm{~g})$, aqueous carbonate species, and the major carbonate minerals (calcite, aragonite, and dolomite). The main question that we addressed is whether computational quantum chemical methods are capable of predicting isotopic fractionation factors across the range of gas, aqueous, and solid-state systems with approximately 1 per mil accuracy, close to the level needed for the calculations to be useful to the geochemical community. 
For this study, we used DFT and MO theory with correlation treated at the $2^{\text {nd }}$ order MøllerPlesset (MP2) level to predict the vibrational frequencies. Given the harmonic frequencies of the minimum-energy structure, one can calculate the reduced partition function ratio (RPFR or $\beta$ ) in the harmonic approximation which can then be used to predict isotope fractionation. The equilibrium isotope fractionation factor (IFF) between species $i$ and $j$ is then given by $\alpha_{i j}=\beta_{i} / \beta_{j}$. $\alpha_{i j}>1$ means that the heavy isotope is concentrated in species $i$.

The simplest approach to the prediction of IFFs is to calculate the frequencies of the individual molecules or ions either as isolated species or using a self-consistent reaction field (SCRF) approach to model the solvent. This simple and computationally efficient approach does not work particularly well. An improved structural model is to embed the solute $\left(\mathrm{CO}_{2}, \mathrm{HCO}_{3}{ }^{-}, \mathrm{CO}_{3}{ }^{2-}\right.$ ) in a number of water molecules to form a "supermolecule" and calculate the second derivatives for these structures. A computational bottleneck in this approach is the generation of independent representative solvent-solute configurations and subsequent optimization of the large supermolecular clusters at a reasonable level of theory. We use DFT-MD simulations as an efficient way to generate representative configurations sampling important areas of the potential energy surface for subsequent study. After extraction of these configurations from the DFT-MD trajectories, they are optimized to a local minimum-energy configuration, often with a higher level of theory. More than ten usable configurations were produced for each species. The vibrational frequencies of cluster models of the solids were calculated by the new Pauling bond strength (PBS)-conserving termination method guaranteed to generate a neutral, autocompensated cluster developed in the Rustad group.

Our calculations based on solvent configuration sampling suggest that with approximately 10 configurations, the standard error in the mean is close to 0.5 per mil and is less important than the computational method/model (e.g., the choice of basis set, the size of the solvation shell chosen to represent the system, and, for DFT, the choice of exchange-correlation functional). This finding is an argument in favor of using the static supermolecule approach rather than a molecular dynamics approach to predict isotopic fractionation. The benefit of including very large numbers of configurations (i.e. more than 10 to 20) through thermal averaging using a dynamics-based method does not appear to be an important factor in predicting isotopic fractionation, although there might be other arguments in favor of the dynamics approach, for example, including anharmonic frequency corrections. Despite the rather wide variation in the particular positions of the major fractionating modes, there appears to be a compensation effect, making the net predicted RPFR relatively insensitive to these variations. This is similar to what was found by us for predictions of the free energy of solvation of ions where a single, dominant configuration provides a very good estimate of this property. It is important to consider more than a single solvent-solute conformer when calculating isotope fractionation factors in aqueous systems to ensure that one does not have an unrepresentative conformer.

Our results showed that the IFFs can be predicted quite accurately with our approach if a large enough cluster is used with an adequate basis set and a reasonable functional. We were surprised by how poorly some of the SCRF approaches worked even when the $1^{\text {st }}$ solvent shell is explicitly included. The PBE/6-31G* are the lowest level calculations which are successful in reproducing relative equilibrium fractionation factors of all major inorganic carbon reservoirs. Improvements are still needed before truly quantitative $\sim 1$ per mil (or less) accuracy can be approached. 
Calculations on the $\mathrm{CO}_{3} \cdot 32 \mathrm{H}_{2} \mathrm{O}^{2-}$ and $\mathrm{HCO}_{3} \cdot 32 \mathrm{H}_{2} \mathrm{O}^{-}$single conformers at the B3LYP/aug-ccpVDZ level are close to this level of accuracy. The prediction of the IFF for $\mathrm{CO}_{2}(\mathrm{~g}) / \mathrm{CO}_{2}(\mathrm{aq})$ is particularly sensitive to the quality of the calculation as the IFF is near zero due to the weak interactions of $\mathrm{CO}_{2}$ in $\mathrm{H}_{2} \mathrm{O}$.

A practical implication of this work for the carbonate system in particular is that we now have a solid foundation for calculations of other aqueous-carbonate systems where experimental measurements are difficult. For example, the isotopic composition of trace carbonate components in minerals formed in paleo-soils is important for the calculation of atmospheric $\mathrm{CO}_{2}$ levels in the geologic past. Establishing that these fractionation factors can be calculated accurately will increase the usefulness of computational chemistry in unraveling the molecularlevel details of paleoclimate reconstruction, helping to answer questions concerning the precise timing of the recording of isotopic signatures during aqueous-mediated crystal growth processes associated with mineral formation in geological environments.

The calculations resulted in the following conclusions. (1) In large clusters with around 30 water molecules forming two solvent shells, conformational variability associated with about 10 configurations gives standard errors in the RFPRs of approximately 0.5 per mil, which is small compared to nonsystematic errors resulting from the choice of computational method. (2) Solvated clusters involving around 30 water molecules, without additional treatment of solvation effects, and with frequencies calculated at the PBE/6-31G* level, are capable of giving qualitative calculation of isotopic fractionation in the gas-phase, aqueous, and solid-state carbonate system with errors $\leq 3$ per mil. Part of this success results from a cancellation of errors associated with using a combination of the modest basis set, which tends to overestimate the reduced partition function ratios, with the PBE exchange-correlation functional, which tends to underestimate them. Our calculations suggest that this error could be reduced to approximately 1 per mil at the B3LYP/aug-cc-pVDZ level. The calculated temperature dependence of the fractionation factors agrees well with experimental measurements. Calculations with smaller numbers of water molecules cannot achieve the level of accuracy of 1 mil, and calculations using only continuum solvent are not even qualitatively correct, regardless of the type of solvation model employed. (3) Calculations on cluster models of carbonate minerals, using the same computational methods as used in modeling the aqueous systems, give good estimates of carbon isotope fractionations for mineral-aqueous-gas systems. Thus, quantum-chemical approaches allow a comprehensive theoretical integration of the relative isotopic fractionation factors for the gas, aqueous, and mineral phases of importance in the Earth's carbon cycle. (4) There is a mixing of the modes of the ion with the solvent leading to more than the minimal number of vibrational modes in the ion being important in determining the isotope fractionation factor. This needs to be further explored experimentally and computationally. One possibility is to measure ${ }^{12,13} \mathrm{C}$ isotope fractionation factors in $\mathrm{D}_{2} \mathrm{O}$ and compare them to measurements in $\mathrm{H}_{2} \mathrm{O}$. The results were published in "Quantum-Chemical Calculations of Carbon-Isotope Fractionation in $\mathrm{CO}_{2}(\mathrm{~g})$, Aqueous Carbonate Species, and Carbonate Minerals,” J. R. Rustad, S. L. Nelmes, V. E. Jackson, and D. A. Dixon, J. Phys. Chem. A, 2008, 112, 542-555.

Boron isotopic fractionation factors The equilibrium constant $\alpha_{34}$ for the isotope exchange reaction ${ }^{10} \mathrm{~B}(\mathrm{OH})_{3}(\mathrm{aq})+{ }^{11} \mathrm{~B}(\mathrm{OH})_{4}{ }^{-}(\mathrm{aq}) \leftrightarrow{ }^{11} \mathrm{~B}(\mathrm{OH})_{3}(\mathrm{aq})+{ }^{10} \mathrm{~B}(\mathrm{OH})_{4}{ }^{-}(\mathrm{aq})$ is the basis for a method 
commonly used to infer the $\mathrm{pH}$ of the ancient oceans and, hence, the $\mathrm{PCO}_{2}$ of the ancient atmosphere. Most estimates of ocean $\mathrm{pH}$ have taken $\alpha_{34}$ to be 1.019, based on early work from 1977 obtained using an empirical valence force field to estimate the vibrational partition function for the gas-phase boric acid and borate ion from which $\alpha_{34}$ can be calculated. Larger $\alpha_{34}$ values may also be implied in work on fluid-silicate melt systems and a new direct determination of $\alpha_{34}$ based on high-sensitivity $\mathrm{pH}$ measurements of the isotope-induced shift in the $\mathrm{pK}_{\mathrm{a}}$ of boric acid. This latter work showed that, at seawater salinities, the equilibrium constant at $25^{\circ} \mathrm{C}$ is $1.0272 \pm$ 0.0006 increasing to $1.0308 \pm 0.0023$ in pure water. Theoretical investigation of the vibrational spectrum of $\mathrm{B}(\mathrm{OH})_{4}{ }^{-}(\mathrm{aq})$ by using ab initio molecular dynamics (AIMD) revealed that a major fractionating vibrational mode had been improperly assigned in the original empirical force field for the borate ion. Thus, the original estimates of $\alpha_{34}$ were based on an erroneously constructed force field, and are incorrect. The larger value for $\alpha_{34}$ has a strong effect on the ocean $\mathrm{pH}$ estimates, leading to values close to one $\mathrm{pH}$ unit more basic than those using the old value of $\alpha_{34}$. This change has resulted in lively debates in the literature as paleoclimatologists adjust to the implications of the new value.

High-accuracy electronic structure calculations would provide additional input into rebuilding the boron $\mathrm{pH}$ proxy. Calculations and simulations of molecular-level interfacial processes governing, for example, boron incorporation into calcite, have the potential to make the technique more accurate. However, to do this effectively, the errors in calculated fractionation factors must be understood as thoroughly as possible. We used both density functional theory (DFT) and correlated molecular orbital (MO) theory to calculate a series of values for $\alpha_{34}$. Our calculations are designed to systematically investigate the effect of the basis set, the exchangecorrelation functional (in the DFT studies), the system size, and solvent conformational variability. We also evaluated the relative performance of DFT and MO theory.

Through a series of DFT and MP2 calculations on hydrated boric acid and borate clusters, $\mathrm{B}(\mathrm{OH})_{3} \cdot n \mathrm{H}_{2} \mathrm{O}$ clusters $(n=0,6,32)$, and $\mathrm{B}(\mathrm{OH})_{4}{ }^{-} \cdot n \mathrm{H}_{2} \mathrm{O}(\mathrm{n}=0,8,11,32)$, we provide an extrapolated value of the equilibrium constant $\alpha_{34}$ for the isotope exchange reaction ${ }^{10} \mathrm{~B}(\mathrm{OH})_{3}(\mathrm{aq})+{ }^{11} \mathrm{~B}(\mathrm{OH}){ }_{4}{ }^{-}(\mathrm{aq})={ }^{11} \mathrm{~B}(\mathrm{OH})_{3}(\mathrm{aq})+{ }^{10} \mathrm{~B}(\mathrm{OH})_{4}{ }^{-}(\mathrm{aq})$. The predicted value of $\alpha_{34}$, expected to be close to the MP2 complete basis set limit, is 1.026-1.028. The wide range of uncertainty arises from uncertain contributions from a $\mathrm{B}(\mathrm{OH})_{3} \cdot 32 \mathrm{H}_{2} \mathrm{O}$ Lewis acid-base complex and from the effects of solvation beyond $n=8$ for borate ion. Our work suggests strongly that improving the accuracy of the estimates provided here would require calculations at the MP2/aug-cc-pVTZ level for on the order of 10 uncorrelated conformations of $\mathrm{B}(\mathrm{OH})_{3} \cdot 32 \mathrm{H}_{2} \mathrm{O}$ and $\mathrm{B}(\mathrm{OH})_{4} \cdot 32 \mathrm{H}_{2} \mathrm{O}$. Until such calculations become possible, DFT calculations on large 32water boric acid and borate clusters at the aug-cc-pVTZ level would allow a more thorough evaluation of the extrapolation procedure developed by us. The results were published in "Calculation of Boron-Isotope Fractionation between $\mathrm{B}(\mathrm{OH})_{3}(\mathrm{aq})$ and $\mathrm{B}(\mathrm{OH})_{4}{ }^{-}(\mathrm{aq})$ " J. R. Rustad, E. J. Bylaska, V. E. Jackson and D. A. Dixon Geochimica et Cosmochimica Acta, 2010, 74, 2843-2850.

Iron isotopic fractionation factors At the $\mathrm{pH}$ values commonly encountered in low-temperature aqueous systems, $\mathrm{Fe}^{2+}(\mathrm{aq})$ coexists with $\mathrm{Fe}(\mathrm{III})$ oxide/oxyhydroxide mineral phases at the mineral-water interface. Due to the low solubilities of the ferric oxide phases, $\mathrm{Fe}^{2+}(\mathrm{aq})$ is the principal mobile iron species. However, because of the interplay of sorption, hydrolysis, 
electron transfer, and re-dissolution, the Fe(II) aqueous-ferric oxide/oxyhydroxide interface is a surprisingly dynamic environment with facile exchange of iron between the mineral and the solution. The rapid shuffling of iron among aqueous species, surface complexes, and oxide phases suggests that equilibrium between the iron isotopes might be readily established in interfacial environments, despite the insolubility of the Fe(III) oxides. The distribution of iron isotopes between aqueous complexes and minerals is an important aid in reconstructing the iron cycle in the early Earth and has important geobiological implications.

Mössbauer and, more recently, inelastic nuclear resonant x-ray scattering (INRXS) spectroscopic measurements have been used to estimate RPFR values for hematite. Mass spectrometric measurements of the iron-isotope compositions of coexisting $\mathrm{Fe}^{3+}(\mathrm{aq})$ and hematite found almost no fractionation between these species. Experimental work on the $\mathrm{Fe}^{2+}$ (aq) and $\mathrm{Fe}^{3+}$ (aq) system provided measurements of equilibrium fractionation between $\mathrm{Fe}^{3+}$ (aq) and $\mathrm{Fe}^{2+}(\mathrm{aq})$, giving $\alpha_{\text {aq3aq2 }}=1.0030$ at $22{ }^{\circ} \mathrm{C}$. Density functional electronic structure calculations of RFPR values for simple hexaaquo models for $\mathrm{Fe}^{2+}(\mathrm{aq})$ and $\mathrm{Fe}^{3+}(\mathrm{aq})$ gave $\alpha_{\text {aq3aq2 }}$ values in good agreement with MC-ICP-MS measurements ( 1.00295 at $\left.22{ }^{\circ} \mathrm{C}\right)$. Subsequent density functional theory (DFT) calculations have confirmed these results. The RPFR estimated from DFT calculations, when combined with the Mossbauer/IRNXS estimate ${ }^{\text {Error! Bookmark not defined. }}$ of $\beta_{\text {ht }}$ predict $\mathrm{Fe}^{3+}(\mathrm{aq})$ to be enriched in ${ }^{56} \mathrm{Fe}^{54} \mathrm{Fe}$ relative the hematite by about +1.4 per mil at $98{ }^{\circ} \mathrm{C}$. In contrast, the MCICP-MS measurements indicate no fractionation. A potential problem with this analysis is that the computed RPFR values and the RPFR values obtained from Mössbauer/IRNXS spectroscopy may each have a different systematic bias that does not cancel when the EIFF is computed from the RPFR ratios. RPFR values obtained from different techniques, or from calculations using different electronic structure methods, for example, different basis sets and/or DFT potentials, are less likely to be accurate than those calculated from RPFRs obtained from the same technique. More recent work has focused on more complex systems involving the fractionation of iron isotopes between $\mathrm{Fe}^{2+}(\mathrm{aq})$ and $\alpha-\mathrm{Fe}_{2} \mathrm{O}_{3}$ in the presence of iron-reducing bacteria. These studies focused on the isotopic fractionation between the $\mathrm{Fe}^{2+}(\mathrm{aq})$ produced by biogenic iron reduction and the hematite on which the bacteria were grown. The measured ${ }^{56} \mathrm{Fe}-{ }^{54} \mathrm{Fe}$ fractionation between hematite and biogenic $\mathrm{Fe}^{2+}$ (aq) was essentially identical to the measured

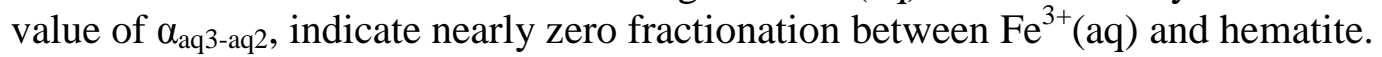

Density functional theory calculations of the reduced partition function ratios for ${ }^{56} \mathrm{Fe}-{ }^{54} \mathrm{Fe}$ exchange on bulk hematite and for the (012) hematite surface, in conjunction with those calculated for $\mathrm{Fe}^{2+}(\mathrm{aq})$ and $\mathrm{Fe}^{3+}(\mathrm{aq})$, with a range of exchange-correlation functionals, indicate that hematite should lie between $\mathrm{Fe}^{3+}(\mathrm{aq})$ (heaviest) and $\mathrm{Fe}^{2+}(\mathrm{aq})$ (lightest) in terms of heavy isotope enrichment. The hematite is represented in both bulk and surface environments. The predicted fractionation between aqueous species $\mathrm{Fe}^{2+}(\mathrm{aq})$ and $\mathrm{Fe}^{3+}(\mathrm{aq})$ is in good agreement with mass-spectrometric measurements. The calculated reduced partition function ratio of hematite is in good agreement with estimates based on Mössbauer and inelastic nuclear resonant X-ray spectroscopy. We find nearly identical reduced partition function ratios for iron residing in bulk hematite and at the (012) hematite surface, indicating that surface-induced fractionation effects are small. We also find that surface conformers having molecularly and dissociatively adsorbed water molecules have similar reduced partition function ratios. Plots of the cumulative reduced partition function ratio as a function of frequency show that the heavy isotope enrichment for $\mathrm{Fe}^{3+}(\mathrm{aq})$ is primarily due to coupling of the octahedral Fe-O stretching and O-Fe-O bending 
motions between $450-500 \mathrm{~cm}^{-1}$ with the wagging vibrations of bound water molecules at frequencies between $800 \mathrm{~cm}^{-1}$ and $1100 \mathrm{~cm}^{-1}$. The discrepancy between the calculated and measured interfacial iron isotope fractionation should encourage detailed structural investigations of the hematite surfaces on which isotope fractionation measurements have been carried out. Given the accuracy demonstrated for the calculations, it is unlikely that the hematite structure at the hematite-water interface resembles a simple termination of the bulk structure. With these calculations, it is possible to estimate both $\alpha_{\mathrm{ht}-\mathrm{aq} 2}$ and $\alpha_{\mathrm{aq} 3 \text {-ht }}$ using reduced partition function ratios obtained from the same theoretical method. By allowing for cancellation of possible systematic errors, this approach should provide a more reliable estimate than using the ratios of RPFR values obtained spectroscopically for hematite and theoretically for $\mathrm{Fe}^{2+/ 3+}$ (aq), or using the ratios of RPFR values obtained using different theoretical methods. Coupled with theoretical calculations, experimental measurements of isotopic composition of iron oxide surfaces provide more valuable information concerning their surface structures than previously thought. The results were published in "Prediction of Iron-Isotope Fractionation Between Hematite $\left(\alpha-\mathrm{Fe}_{2} \mathrm{O}_{3}\right)$ and Ferric and Ferrous Iron in Aqueous Solution from Density Functional Theory,” J.R. Rustad and D.A. Dixon, J. Phys. Chem. A, 2009, 113, 12249-12255.

Magnesium and calcium isotopic fractionation factors Isotopic fractionation between chemical species in mineral and solution environments have the potential to reveal detailed information on the interaction between the lithosphere, hydrosphere, and biosphere through geologic time. Magnesium, calcium, and iron isotope exchange between water and carbonate minerals calcite $\left(\mathrm{CaCO}_{3}, \mathrm{cc}\right)$, magnesite $\left(\mathrm{MgCO}_{3}, \mathrm{~ms}\right)$ and dolomite $\left(\mathrm{CaMg}\left(\mathrm{CO}_{3}\right)_{2}\right.$, dm) are particularly important for indicating chemical conditions in marine environments with implications for long term variations in continental weathering, paleoredox conditions, and climate. Measurements of drip water in contact with magnesium-bearing calcite $\left[\left(\mathrm{Mg}_{0.005-0.075} \mathrm{Ca}_{0.995-0.925}\right) \mathrm{CO}_{3}\right]$ yield $\Delta^{26 / 24} \mathrm{Mg}_{c c-a q}=-2.8$ per mil to -2.6 per mil. Calcite precipitated inorganically in the laboratory gave $\Delta^{26 / 24} \mathrm{Mg}_{c c-a q}=-2.4$ per mil at $25{ }^{\circ} \mathrm{C}$. Among the carbonate minerals, dolomite tends to be most the most enriched in ${ }^{26} \mathrm{Mg}$, followed by magnesite, with magnesium-bearing calcite being the most depleted. Early laboratory measurements gave $\Delta^{44 / 40} \mathrm{Ca}_{c c-a q}$ less than 2 per mil. More recent measurements have indicated values of $\Delta^{44 / 40} \mathrm{Ca}_{c c-a q}$ from -1.5 per mil to -0.5 per mil; however, the two most recent studies conclude that any isotopic compositional difference between calcite and water is less than 0.05 per mil. The relationship of these measurements to the value of the equilibrium constant for mineral-aqueous isotope fractionation is unclear because it is difficult to prove that the measured distributions are truly representative of equilibrium conditions. For example, fractionation may be controlled by intermediate surface complexes forming during growth or dissolution that "lock in" the isotope signature well before equilibrium can be established. Thus far, there is only one direct double-cell electrochemical measurement of the equilibrium constant $K_{c c-a q}{ }^{44 / 40} \mathrm{Ca}$ giving $1.08 \pm 0.02$, a value that is completely inconsistent with measurements of $\Delta^{44 / 40} \mathrm{Ca}_{c c-a q}$. It was argued that non-fractionating kinetic precipitation processes overprinted the equilibrium isotopic fractionation. The prior work presented

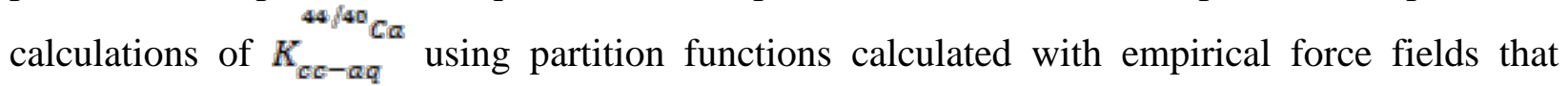
yielded fractionations much closer to the earlier measurements. The authors suggested a "structureless" first solvation shell for the $\mathrm{Ca}^{2+}(\mathrm{aq})$ structure as the only means by which they could obtain $\mathrm{Ca}^{2+}(\mathrm{aq})$ frequencies sufficiently low to recover a reduced partition function ratio of 
the right magnitude to reconcile with their measured equilibrium constant. It is important to resolve the discrepancy the different studies because the electrochemical measurements, being reversible, yield the only data where equilibrium can be demonstrated without resorting to an extrapolation over long time scales.

We used electronic structure calculations to predict the equilibrium constant $K_{m n-a q}^{h / l}$ (the equilibrium constant for equation (1)

$$
{ }^{l} \mathrm{M}_{\mathrm{mn}}(\mathrm{s})+{ }^{h} \mathrm{M}^{2+}(\mathrm{aq}) \leftrightarrow{ }^{h} \mathrm{M}_{\mathrm{mn}}(\mathrm{s})+{ }^{l} \mathrm{M}^{2+}(\mathrm{aq})
$$

where $\mathrm{M}_{\mathrm{mn}}$ indicates $\mathrm{M}$ in the mineral phase and $\mathrm{M}^{2+}(\mathrm{aq})$ represents the aquo ion (or aquo complex), for the ${ }^{26 / 24} \mathrm{Mg}$ and ${ }^{44 / 40} \mathrm{Ca}$ isotope exchange reactions between carbonate phases and the uncomplexed $\mathrm{Mg}$ or Ca aquo ion. To the extent that the harmonic approximation is obeyed, and that an accurate potential energy surface for atomic motion is recovered, the quantum mechanical calculations provide an unambiguous prediction of $K_{m n-a q}^{h / l}$, reflecting direct partitioning between the bulk mineral and aqueous environments without the complications of surfaces and kinetics. Direct $a b$ initio knowledge of the idealized equilibrium constant is useful in establishing the extent to which the idealized equilibrium represented by Equation (1), without such complications, is relevant to mineral-aqueous fractionation. The prediction of isotopic fractionation between a metal ion in solution and in a mineral presents particular theoretical challenges. Calculations of this type do not benefit from cancellation of errors to the same extent as isotope fractionation calculations in other contexts, such as between two oxidation states or spin states of the same ion in the same coordination environment. For example, while recent electronic structure calculations on iron-isotope fractionation agree with experimental measurements of ${ }^{56 / 54} \mathrm{Fe}$ fractionation between ferrous and ferric aquo ions, there remains a significant discrepancy between the calculated and measured fractionation between the ferric aquo ion and hematite and also between the calculated and measured fractionation between the ferrous aquo ion and siderite.

Equilibrium constants calculated using density functional theory for the equilibrium exchange of ${ }^{26} \mathrm{Mg}$ and ${ }^{24} \mathrm{Mg}$ between magnesium bearing carbonates and aqueous solution give values for $10^{3} \ln K_{m n-a q}^{{ }^{26 / 24} \mathrm{Mg}}$ of $-5.3,-1.1$, and +1.1 for calcite, magnesite, and dolomite, respectively, at or near the B3LYP/6-311++G(2d,2p) level. Although the order of heavy isotope enrichment Mg-calcite < magnesite < dolomite is reproduced, the fractionation predicted for Mgcalcite is low relative to field and laboratory measurements. The calculated value for $10^{3} \ln K_{c c-a q}^{44 / 40} \mathrm{Ca}$ at the same level of theory is +4.1 for a 7 -fold coordinated $\mathrm{Ca}^{2+}$ (aq) complex and

+1.5 for a 6-fold coordinated $\mathrm{Ca}^{2+}$ (aq) complex. While the latter value may be in better agreement with the range of values for $\Delta^{44 / 40} \mathrm{Ca}_{c c-a q}$ currently reported in the literature, the

former model is more likely to be a correct representation of the aquo ion. Given the level disagreement between the electrochemically measured $K_{c c-a q}^{44 / 40} c a$ and our electronic structure 
calculations, it can be ascertained that no reasonable correction to the RPFR for the $\mathrm{Ca}^{2+}(\mathrm{aq})$ ion

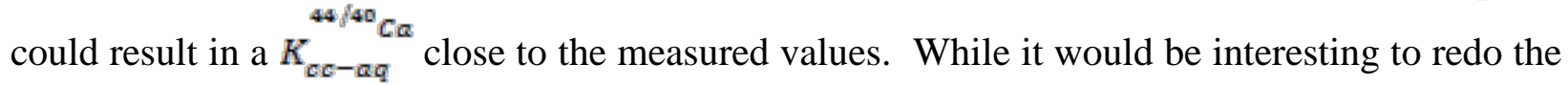
electrochemical measurements, the precision of these measurements, reported as \pm 20 per mil in $10^{3} \ln K_{c c-a q}^{44 / 40} C a$, is not sufficient to resolve either the disagreement between the two values of $\Delta^{44 / 40} \mathrm{Ca}_{c c-a q}$ purported to correspond to $10^{3} \ln K_{c c-a q}^{44 / 40} \mathrm{Ca}$ nor the disagreement between the $\Delta^{44 / 40} \mathrm{Ca}_{e c-a q}$ and the calculated $K_{c c-a q}^{44 / 40} \mathrm{Ca}$ presented here. In contrast to the $\mathrm{Mg}$ and Ca carbonate system, the improved RPFR values presented here for $\mathrm{Fe}^{2+}(\mathrm{aq})$ and $\mathrm{Fe}^{3+}(\mathrm{aq})$, now yield excellent agreement between the calculated and measured siderite-Fe ${ }^{2+}$ (aq) $K_{s r-a q}^{56 / 54^{F}}$, as well as the calculated and measured hematite- $\mathrm{Fe}^{3+}(\mathrm{aq}) K_{h t-a q}^{56 / 54^{F e}}$. This suggests that it is possible to calculate reliable isotope fractionation factors for such cationic systems using the approach described above.

The comparison with measured values of $\Delta^{h / l} \mathrm{M}_{m n-a q}$ for the magnesium, calcium, and iron isotope exchange equilibria imply that none of the values reported for mineral-solution isotopic differences represent equilibrium isotope fractionations. It seems unlikely that both of the calculated values of $10^{3} \ln K_{c c-a q}^{{ }^{26 / 24} \mathrm{Mg}}$ and $10^{3} \ln K_{c c-a q}^{44 / 40} \mathrm{Ca}$ could be brought into agreement with measured values of $\Delta^{26 / 24} \mathrm{Mg}_{c c-a q}$ and $\Delta^{44 / 40} \mathrm{Ca}_{c c-a q}$, respectively through any reasonable correction of the computed RPFR values. The computed RPFR values for the mineral environments appear to be nearly converged. While corrections to the RPFR values of the aquo complexes at the MP2 level might improve the level of agreement for calcite, it is unlikely that an equal mixture of 6-fold and 7-fold coordinated $\mathrm{Ca}^{2+}$ (aq) would yield a fractionation of less than $+1.0-+2.0$ per mil at the MP2 level, even assuming no compensating change for the mineral RPFR . Moreover, any improvements in the level of agreement for calcite are likely to result in worse agreement for the $\mathrm{Mg}^{2+}(\mathrm{aq})$-calcite fractionation. It should also be noted that the measured carbon isotope fractionation between aqueous bicarbonate and calcite is predicted to within 0.5 per mil using electronic structure calculations similar to those used in this study.Error! Bookmark not defined.

Certain combinations of exchange-correlation functionals and basis sets can sometimes yield a value consistent with expectations. For example, the BP86/6-311++G(2d,2p) and BP86/DZVP calculation for $\mathrm{Mg}$ isotope exchange between calcite and aqueous solution, give isotope distributions very close to the observed isotope fractionations, bracketing the value from above 
and below, respectively. However, a strong theoretical foundation for understanding isotope fractionation effects cannot be based on such chance occurrences, and it would be misleading to conclude that the BP86 functional "works better" than the B3LYP functional for such calculations in general as some other system (for example the $\mathrm{Ca}^{2+}(\mathrm{aq}$ )-calcite system investigated here) might behave differently. The theoretical methods are more powerful when applied simultaneously to multiple, but closely related, systems.

From a methodological point of view, it has been determined that for $\mathrm{Mg}^{2+}(\mathrm{aq})$, adding continuum solvation beyond an explicit second shell of solvating water molecules gives results very close to the average RPFR found for a series of ten conformations of $\mathrm{Mg}\left(\mathrm{H}_{2} \mathrm{O}\right)_{33}{ }^{2+}$. It is also evident that the use of a good basis set is much more important for calculating the reduced partition function ratios for the clusters representing the aqueous species than for the clusters representing the solid state. Thus, it is the level of computational treatment of the aqueous environment, more than the mineral environment that governs the overall quality of the predicted mineral-aqueous fractionation. Finally, calculated RPFR values are surprisingly insensitive of the results to fixing the positions of all atoms except for the central metal and its immediate first coordination shell ligands, allowing accurate use of $\mathrm{Mg}\left(\mathrm{CO}_{3}\right)_{6}{ }^{10-}$ and $\mathrm{Mg}^{2+}\left(\mathrm{H}_{2} \mathrm{O}\right)_{6}$ when embedded in a fixed array of atoms (with appropriate overall charge of +10 for the hexacarbonate complex). All of these factors taken together put $a b$ initio molecular orbital calculations at the MP2 level with large basis sets within reach for these systems.

The next step for theoretical investigations would be to calculate RPFR values using MP2 perturbation theory with large basis sets such as aug-cc-pVTZ. The computational savings resulting from fixing atoms beyond the immediate coordinating ligands would allow the computations to be carried out using a $\mathrm{M}\left(\mathrm{CO}_{3}\right)_{6}{ }^{10-}$ core, embedded in a charge-compensating shell representing the environment, and $\mathrm{M}^{2+}\left(\mathrm{H}_{2} \mathrm{O}\right)_{6}$ or $\mathrm{M}^{2+}\left(\mathrm{H}_{2} \mathrm{O}\right)_{7}$ molecule embedded in a fixed aqueous $2^{\text {nd }}$ shell surrounded by continuum solvent. Our representation of the shell surrounding the $\mathrm{M}\left(\mathrm{CO}_{3}\right)_{6}{ }^{10-}$ ion, and possibly even the $\mathrm{M}\left(\mathrm{H}_{2} \mathrm{O}\right)_{6}{ }^{2+}$ ion might be made much more efficient by representing the core using an quantum-mechanical electronic-structure calculation and the shell using a molecular-mechanics force field in a QM/MM calculation. The loss of accuracy for the shell atoms would likely be small as these are already treated with a small 3-21G basis set in the calculations presented here. The main issue may simply be to compensate the charge properly. In fact, a molecular mechanics representation might improve the representation of the shell atoms. If successful, this would make calculations at the MP2 level, with large basis sets, feasible for these systems in the context of QM-MM. Previous work on aqueous anionic systems and neutral systems show that DFT and MP2 can yield quite different predictions for the equilibrium constants for isotope exchange reactions. This work is published in "Isotopic Fractionation of $\mathrm{Mg}^{2+}(\mathrm{aq}), \mathrm{Ca}^{2+}(\mathrm{aq})$, and $\mathrm{Fe}^{2+}(\mathrm{aq})$ with Carbonate Minerals," J. R. Rustad, W. H. Casey, Q.-Z. Yin, E. J. Bylaska, A. R. Felmy, S. A. Bogatko V. E. Jackson and D. A. Dixon, Geochimica et Cosmochimica Acta, 2010, 74, 6301-6323.

\section{$\mathrm{CO}_{2}$ hydration chemistry}

Carbon dioxide has a substantial impact on the environment due to the combustion of fossil fuels. A consensus has emerged that increasing levels of $\mathrm{CO}_{2}$ in the atmosphere from anthropogenic sources correlate with higher global temperatures. A key constraint on 
atmospheric $\mathrm{CO}_{2}$ is the solubility of $\mathrm{CO}_{2}$ in the oceans. Due to its role in the $\mathrm{pH}$ regulation of blood in the human body, the reversible hydration reaction of $\mathrm{CO}_{2}$ is of biological importance. The photo-respiration of plants, consisting of $\mathrm{CO}_{2}$-uptake and $\mathrm{O}_{2}$-release from photosynthesis, is a fundamental process in plant physiology. There are many proposals for sequestering atmospheric $\mathrm{CO}_{2}$ upon generation. One strategy is injection in deep geological formations or in the ocean. $\mathrm{CO}_{2}$ sequestration can occur by the formation of hydrogen-bonded water cages leading to the formation of gas hydrate clusters (clathrates). Due to the high solubility of carbon dioxide in water, when $\mathrm{CO}_{2}\left(\mathrm{H}_{2} \mathrm{O}\right)_{\mathrm{n}}$ hydrates dissociate, the dissolution of carbon dioxide in water can form carbonic acid $\mathrm{H}_{2} \mathrm{CO}_{3}$ and/or its conjugate bases. The hydration reaction of $\mathrm{CO}_{2}$ forming $\mathrm{H}_{2} \mathrm{CO}_{3}$ in neutral aqueous media is thus of interest. Carbonic acid is a stable discrete molecular species, not only in the gas phase but also in a solid ice matrix at temperature below that of liquid nitrogen, in aqueous solution, and likely on acid-treated carbonate mineral surfaces. In solid conditions, the dimer or oligomers of $\mathrm{H}_{2} \mathrm{CO}_{3}$ appear to be the more dominant forms. Although a consensus has emerged on the active involvement of a water oligomer $n\left(\mathrm{H}_{2} \mathrm{O}\right)$, rather than just a water monomer ( $\mathrm{n}=1$ ), in the hydration reaction of $\mathrm{CO}_{2}$ to form $\mathrm{H}_{2} \mathrm{CO}_{3}$, the actual number of participating water molecules and the details of their catalytic action remains a matter of debate. In view of the importance of the $\mathrm{CO}_{2}$ hydration reaction to form $\mathrm{H}_{2} \mathrm{CO}_{3}$, we have performed detailed quantum chemical calculations on the reaction

$$
\mathrm{CO}_{2}+\mathrm{nH}_{2} \mathrm{O} \rightarrow \mathrm{H}_{2} \mathrm{CO}_{3}+(\mathrm{n}-1) \mathrm{H}_{2} \mathrm{O}
$$

for $\mathrm{n}=1-4$. We predicted critical thermochemical parameters and explored relevant portions of the potential energy surfaces in both the gas and aqueous phases in order to distinguish potentially different mechanisms. We used a highly accurate computational approach, CCSD(T) extrapolated to the complete basis set limit for the calculations coupled with seld consistent reaction fields to model the extended solvent effects.

Thermochemical parameters of carbonic acid and the stationary points on the neutral hydration pathways of carbon dioxide, $\mathrm{CO}_{2}+\mathrm{nH}_{2} \mathrm{O} \rightarrow \mathrm{H}_{2} \mathrm{CO}_{3}+(\mathrm{n}-1) \mathrm{H}_{2} \mathrm{O}$, with $\mathrm{n}=1,23$, and 4 were calculated using geometries optimized at the MP2/aug-cc-pVTZ level. Coupled-cluster theory $(\operatorname{CCSD}(\mathrm{T}))$ energies were extrapolated to the complete basis set limit in most cases and then used to evaluate heats of formation. A high energy barrier of $\sim 50 \mathrm{kcal} / \mathrm{mol}$ was predicted for the addition of one water molecule to $\mathrm{CO}_{2}(\mathrm{n}=1)$. This barrier is lowered in cyclic $\mathrm{H}$-bonded systems of $\mathrm{CO}_{2}$ with water dimer and water trimer in which pre-association complexes are formed with binding energies of $\sim 7$ and $13 \mathrm{kcal} / \mathrm{mol}$, respectively. For $\mathrm{n}=2$, a trimeric sixmember cyclic transition state has an energy barrier of $\sim 33$ (gas phase at $0 \mathrm{~K}$ ) and a free energy barrier of $\sim 31 \mathrm{kcal} / \mathrm{mol}$ (in a continuum solvent model of water at $298 \mathrm{~K}$ ), relative to the precomplex. For $\mathrm{n}=3$, two reactive pathways are possible with the first having all three water molecules involved in hydrogen transfer via an eight-member cycle, and in the second, the third water molecule is not directly involved in the hydrogen transfer but solvates the $\mathrm{n}=2$ transition state. In the gas phase, the two transition states have comparable energies of $\sim 15 \mathrm{kcal} / \mathrm{mol}$ relative to the separated reactants. The first path is favored over in aqueous solution by $\sim 5$ $\mathrm{kcal} / \mathrm{mol}$ on free energy, due to the formation of a structure resembling a $\left(\mathrm{HCO}_{3}{ }^{-} / \mathrm{H}_{3} \mathrm{OH}_{2} \mathrm{O}^{+}\right)$ion pair. Bulk solvation reduces the free energy barrier of the first path by $\sim 10 \mathrm{kcal} / \mathrm{mol}$ for a free energy barrier of $\sim 22 \mathrm{kcal} / \mathrm{mol}$ at $298 \mathrm{~K}$ for the $\left(\mathrm{CO}_{2}+3 \mathrm{H}_{2} \mathrm{O}\right)_{\text {aq }}$ reaction. For $\mathrm{n}=4$, the transition state in which a three-water chain takes part in the hydrogen transfer while the fourth water microsolvates the cluster, is energetically more favored than transition states incorporating two or four active water molecules. Energy barrier of $\sim 20$ (gas phase at $0 \mathrm{~K}$ ) and free energy barrier 
of $\sim 19$ (in water at $298 \mathrm{~K}$ ) $\mathrm{kcal} / \mathrm{mol}$ were derived for the $\mathrm{CO}_{2}+4 \mathrm{H}_{2} \mathrm{O}$ reaction and again formation of an ion pair is important. The calculated results confirm the crucial role of direct participation of three water molecules $(n=3)$ in the eight-member cyclic TS for the $\mathrm{CO}_{2}$ hydration reaction. Carbonic acid and its water complexes are consistently higher in energy (by $\sim 6-7 \mathrm{kcal} / \mathrm{mol}$ ) than the corresponding $\mathrm{CO}_{2}$-complexes, and can undergo more facile waterassisted dehydration processes. Diagrams of the potential energy surfaces for $n=1-3$ are shown below in Figures 1 - 3. This work is published in "Mechanism of the Hydration of Carbon Dioxide: Direct Participation of $\mathrm{H}_{2} \mathrm{O}$ versus Microsolvation,” M. T. Nguyen, M. H. Matus, V. E. Jackson,V. T. Ngan, J. R. Rustad, and D. A. Dixon, J. Phys. Chem. A, 2008, 112, 10386-10398.

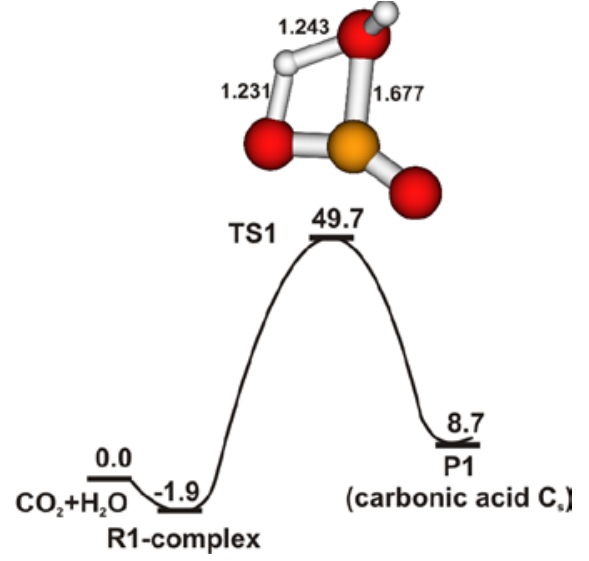

Figure 1. Potential energy profile for $\mathrm{CO}_{2}+$ $\mathrm{H}_{2} \mathrm{O}$ at $0 \mathrm{~K}$. Relative energies in $\mathrm{kcal} / \mathrm{mol}$ obtained from calculated heats of formation. MP2/aVTZ optimized distances of the transition state TS1 are given in $\AA$

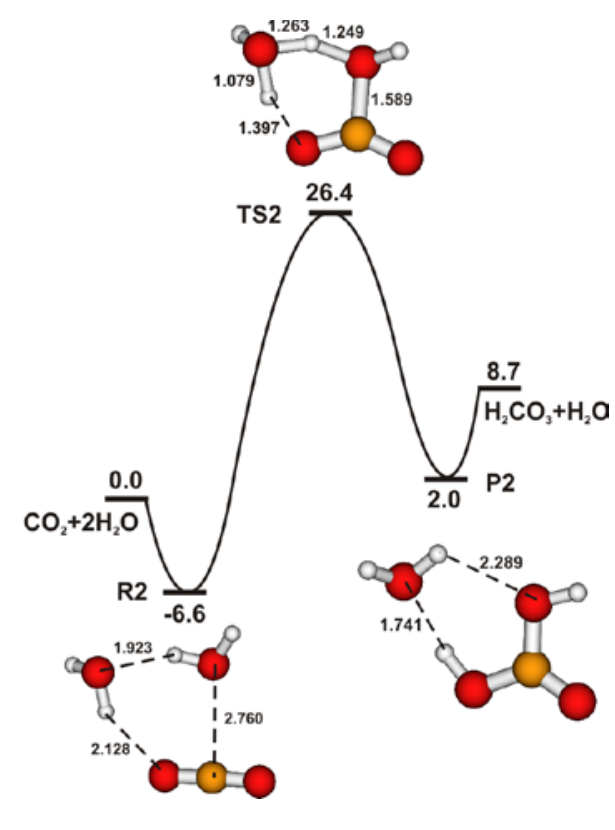

Figure 2. Potential energy profile for $\mathrm{CO}_{2}+$ $2 \mathrm{H}_{2} \mathrm{O}$ at $0 \mathrm{~K}$. Relative energies in $\mathrm{kcal} / \mathrm{mol}$ obtained from calculated heats of formation. MP2/aVTZ optimized distances of the stationary points are given in $\AA$.

\section{Atmospheric chemistry}

Chlorine oxides Since Molina and Rowland's paper on the role of chlorine atoms in the destruction of ozone in the stratosphere, there has been substantial interest in the nature of the chlorine oxides, notably ClOOCl which is formed by the dimerization of two ClO molecules. This molecule photodissociates to form $\mathrm{ClOO}$ and $\mathrm{Cl}$, and the $\mathrm{ClOO}$ molecule rapidly decomposes to form $\mathrm{Cl}+\mathrm{O}_{2}$. The $\mathrm{Cl}$ atoms then participate in the usual $\mathrm{Cl}$ catalyzed destruction of $\mathrm{O}_{3}$ via reaction (3).

$$
\mathrm{Cl}+\mathrm{O}_{3} \rightarrow \mathrm{ClO}+\mathrm{O}_{2}
$$

There is renewed interest in the ultraviolet absorption spectrum of $\mathrm{ClOOCl}$ due to a recent study by Pope et. al which showed that the photoabsorption cross sections of $\mathrm{ClOOCl}$ at wavelengths longer than $300 \mathrm{~nm}$ are significantly lower than all previous measurements or estimates. This is critical as the absorption at wavelengths longer than $300 \mathrm{~nm}$ is the most important for predicting the photolysis rate of $\mathrm{ClOOCl}$ as ozone absorbs most of the shorter wavelengths in this region of the atmosphere. The latest experimental work used very carefully purified $\mathrm{ClOOCl}$ in order to minimize the contributions of impurities that could increase the longer wavelength cross-section. 
Because photolysis of $\mathrm{ClOOCl}$ is the rate limiting step in the loss of polar ozone, it is critical to understand different potential absorbers. There is substantial concern in the atmospheric modeling community as to what the correct chemistry is to account for ozone depletion in the stratosphere. We have used high level molecular orbital theory following the methods we developed for accurate thermochemical predictions to predict the structures, vibrational frequencies, and heats of formation of the $\mathrm{Cl}_{2} \mathrm{O}_{2}$ isomers and additional compounds with the stoichiometry $\mathrm{Cl}_{x} \mathrm{O}_{y}$ for $x, y=1,2$.

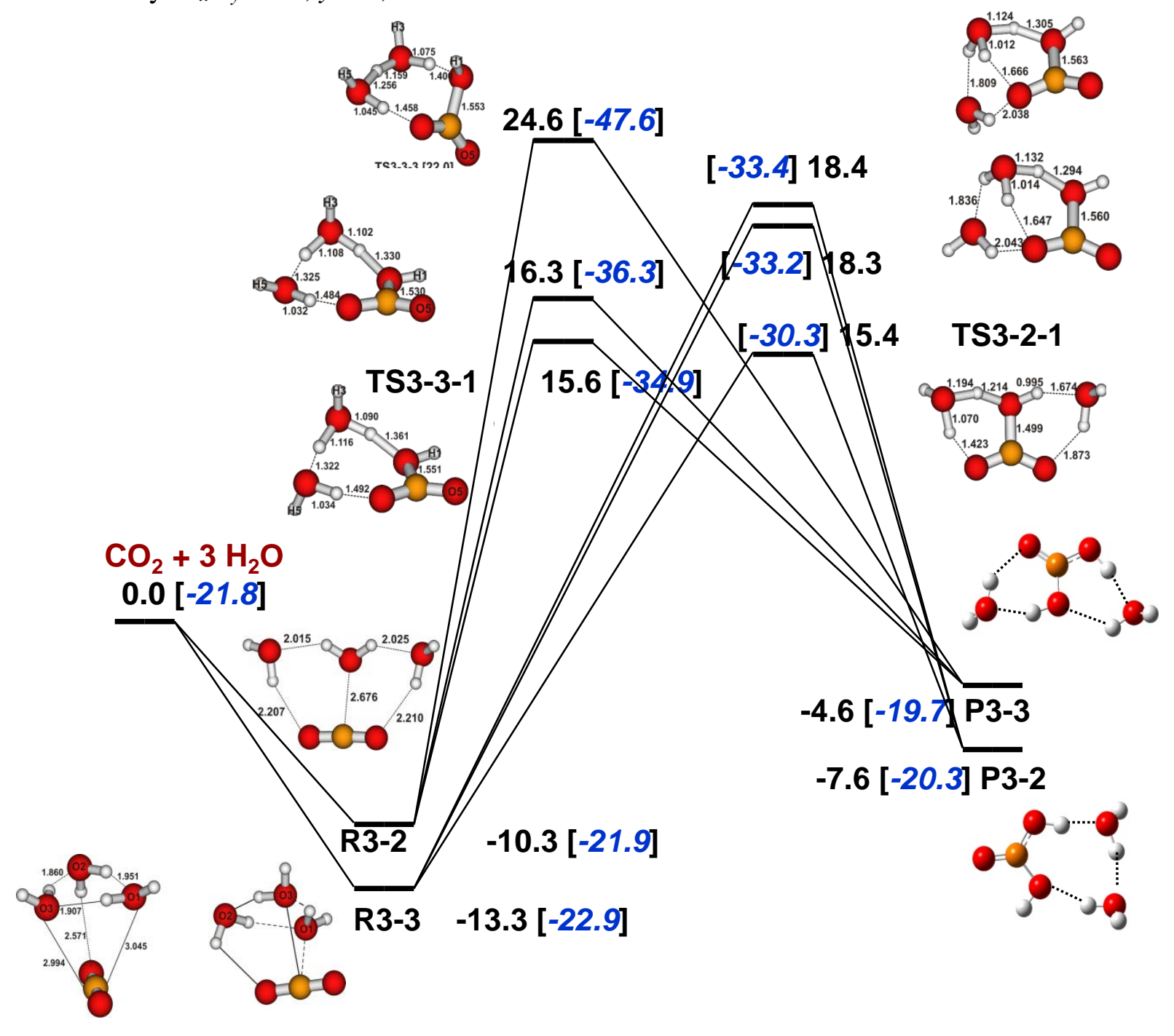

Figure 3. Potential energy profiles in kcal/mol for six channels of the $\mathrm{CO}_{2}+3 \mathrm{H}_{2} \mathrm{O}$ addition reaction at the CCSD(T)/CBS + all corrections at $0 \mathrm{~K}$ in black. The values in blue are free energies from gas phase CCSD(T)/CBS values at $298 \mathrm{~K}$ plus a correction for solvent effects at the COSMO/MP2/aVTZ level.

The calculated heats of formation (Table 1) for the diatomics $\mathrm{Cl}_{2}$ and $\mathrm{ClO}$ are within 0.5 $\mathrm{kcal} / \mathrm{mol}$ of the experimental values. For the triatomics $\mathrm{ClOCl}$ and $\mathrm{OClO}$, the calculated heats of formation are also within $0.5 \mathrm{kcal} / \mathrm{mol}$ of experiment if the most recent value of $23.53 \pm 0.24$ $\mathrm{kcal} / \mathrm{mol}$ from the photodissociation dynamics study of Davis and Lee is used for OClO. For 
$\mathrm{ClOOCl}$, the calculated heat of formation is $1.1 \mathrm{kcal} / \mathrm{mol}$ higher than the experimental value from Sander and co-workers which has an error bar of $0.7 \mathrm{kcal} / \mathrm{mol}$. Our value for $\mathrm{ClOOCl}$ is in excellent agreement with the value of $31.3 \pm 0.7 \mathrm{kcal} / \mathrm{mol}$ obtained by both Cox and Hayman and the recent photoionization study by Plenge et al. We note that the less positive experimental heats of formation of $\mathrm{OClO}$ and $\mathrm{ClOOCl}$ are from the same study ${ }^{\text {Error! Bookmark not defined. and }}$ appear to be off by 0.8 to $1.0 \mathrm{kcal} / \mathrm{mol}$. Our calculated heats of formation should be accurate to $\pm 1.0 \mathrm{kcal} / \mathrm{mol}$ and we would expect the relative energies to be better than $\pm 1 \mathrm{kcal} / \mathrm{mol}$. We predict that $\mathrm{ClClO}_{2}$ is $3.1 \mathrm{kcal} / \mathrm{mol}$ more stable than $\mathrm{ClOOCl}$ at $298 \mathrm{~K}$ on the enthalpy scale and that $\mathrm{ClClO}_{2}$ will be favored by an additional $0.8 \mathrm{kcal} / \mathrm{mol}$ on the free energy scale. There is a strong basis set dependence on the relative energy and one needs large basis sets to get this energy difference correct. It is not until the aug-cc-pVQZ basis is used that $\mathrm{ClClO}_{2}$ becomes more stable than $\mathrm{ClOOCl}$ in terms of the electronic energy. Thus lower level theories such as G2 do not incorporate large enough basis sets to get this isomer energy differences correct. The ClOClO isomer is predicted to be $8.3 \mathrm{kcal} / \mathrm{mol}$ above $\mathrm{ClOOCl}$ at $298 \mathrm{~K}$ and $11.4 \mathrm{kcal} / \mathrm{mol}$ above $\mathrm{ClClO}_{2}$. Our results suggest that one must take care in the synthesis of $\mathrm{ClOOCl}$ to avoid the formation of $\mathrm{ClClO}_{2}$, for example on surfaces.

Table 1. Calculated Heats of formation $\left(\mathrm{kcal} \mathrm{mol}^{-1}\right)$ at $0 \mathrm{~K}$ and $298 \mathrm{~K}^{\mathrm{a}}{ }^{\mathrm{a}}$

\begin{tabular}{|c|c|c|c|}
\hline Molecule & $\Delta H_{f}(0 \mathrm{~K})_{\text {calc }}$ & $\Delta H_{f}(298 \mathrm{~K})_{\text {calc }}$ & Reference $\Delta H_{f}(298 \mathrm{~K})$ \\
\hline $\mathrm{ClOOCl}$ & 32.9 & 31.6 & $30.5 \pm 0.7,31.3 \pm 0.7^{b}$ \\
\hline $\mathrm{ClOClO}$ & 41.0 & 39.9 & 41.9 \\
\hline $\mathrm{ClClO}_{2}$ & 29.4 & 28.5 & $36.9^{\mathrm{c}}$ \\
\hline $\mathrm{OClO}\left({ }^{2} \mathrm{~B}_{1}\right)$ & 24.5 & 23.9 & $22.6 \pm 0.3,23.53 \pm 0.24^{\mathrm{d}}$ \\
\hline $\mathrm{ClOCl}$ & 19.3 & 18.9 & $19.4 \pm 0.4$ \\
\hline $\operatorname{ClClO}\left({ }^{1} A^{\prime}\right)$ & 32.2 & 31.9 & $22 \pm 7$ \\
\hline $\mathrm{ClClO}\left({ }^{3} \mathrm{~A}^{\prime \prime}\right)^{\mathrm{e}}$ & 52.2 & 52.4 & \\
\hline $\mathrm{ClO}^{\mathrm{t}}$ & 24.8 & 24.8 & $24.29 \pm 0.03$ \\
\hline $\mathrm{Cl}_{2}$ & -0.2 & -0.2 & 0.0 \\
\hline
\end{tabular}

In order to provide information about the observations of the photoabsorption of $\mathrm{ClOOCl}$, we calculated the vertical electronic excitation energies for $\mathrm{ClOOCl}, \mathrm{ClClO}_{2}$, and $\mathrm{ClOClO}$ at the EOM-CCSD/aug-cc-pV(T+d)Z level (EOM = equation of motion). The spectra arising from the excited singlet states of all three species are shown in Figure 4. An examination of the excited states of $\mathrm{ClOOCl}$ shows that there are only two weak absorption bands to the red of $245 \mathrm{~nm}$ at about $310 \mathrm{~nm}$. This is consistent with the recently reported spectrum ${ }^{\text {Error! Bookmark not defined. }}$ of ClOOCl which shows much lower intensities in the tail to the visible than previously reported. This spectrum clearly demonstrates that singlet states of $\mathrm{ClClO}_{2}$ absorb to longer wavelengths in the visible than do the singlet states of ClOOCl. Our calculated spectrum for $\mathrm{ClClO}_{2}$ is consistent with that reported by Willner and coworkers. Assuming that the ratio of the oscillator strengths dominates the ratio of intensities, our results are in qualitative agreement with the results of the intensity ratios at 250 and $350 \mathrm{~nm}$ observed by Pope et al., which show a large value for this ratio in the range of 300. Our results show that the $\mathrm{ClClO}_{2}$ isomer is a significant absorber in the near UV region and its potential presence needs to be accounted for in experiments. In particular, it has two significantly more absorbing bands to the red of the lowest absorption band of $\mathrm{ClOOCl}$. We also calculated the oscillator strengths of the triplet states of $\mathrm{ClOOCl}$ and $\mathrm{ClClO}_{2}$ at the CASSCF level using the full Breit-Pauli spin orbit operator in the linear response CASSCF 
calculations with the aVTZ $(\mathrm{ClOOCl})$ and $\mathrm{aV}(\mathrm{T}+\mathrm{d}) \mathrm{Z}\left(\mathrm{ClClO}_{2}\right)$ basis sets. The oscillator strength of the more intense (of the two lowest lying triplets) $\mathrm{a}^{3} \mathrm{~B}$ transition for $\mathrm{ClOOCl}$ is about an order of magnitude less than that of the more intense (of the two lowest lying singlets) $\mathrm{A}^{1} \mathrm{~B}$ transition at the CASSCF level. The low lying triplet state has been shown to smoothly dissociate to $\mathrm{Cl}+$ ClOO. Thus, in the region $>370 \mathrm{~nm}$ for $\mathrm{ClOOCl}$, the triplet state could be the most intense contributor to the photodissociation of $\mathrm{ClOOCl}$ as the peak of the lowest lying singlet is predicted to be at $310 \mathrm{~nm}$.

The oscillator strengths for $\mathrm{ClClO}_{2}$ for the three lowest energy transitions are $7.0 \mathrm{x}$ $10^{-8}\left({ }^{3} \mathrm{~A}^{\prime}, 515 \mathrm{~nm}\right), 5.5 \times 10^{-}$ ${ }^{5}\left({ }^{3} \mathrm{~A} ", 382 \mathrm{~nm}\right)$, and $1.5 \mathrm{x}$ $10^{-4} \quad\left({ }^{3} \mathrm{~A}^{\prime}, \quad 350 \mathrm{~nm}\right)$ in comparison to the values of $5.5 \times 10^{-6}\left({ }^{3} \mathrm{~B}, 389 \mathrm{~nm}\right)$ and $1.5 \times 10^{-5}\left({ }^{3} \mathrm{~A}, 385 \mathrm{~nm}\right)$ for ClOOCl. The most intense low lying triplet transition in $\mathrm{ClClO}_{2}$ has an oscillator strength that is almost an order of magnitude more intense than that in ClOOCl. This work was published as a Letter in " $\mathrm{ClClO}_{2}$ Is the Most Stable Isomer of $\mathrm{Cl}_{2} \mathrm{O}_{2}$. Accurate Coupled Cluster Energetics and Electronic Spectra of $\mathrm{Cl}_{2} \mathrm{O}_{2}$ Isomers," M.H. Matus,

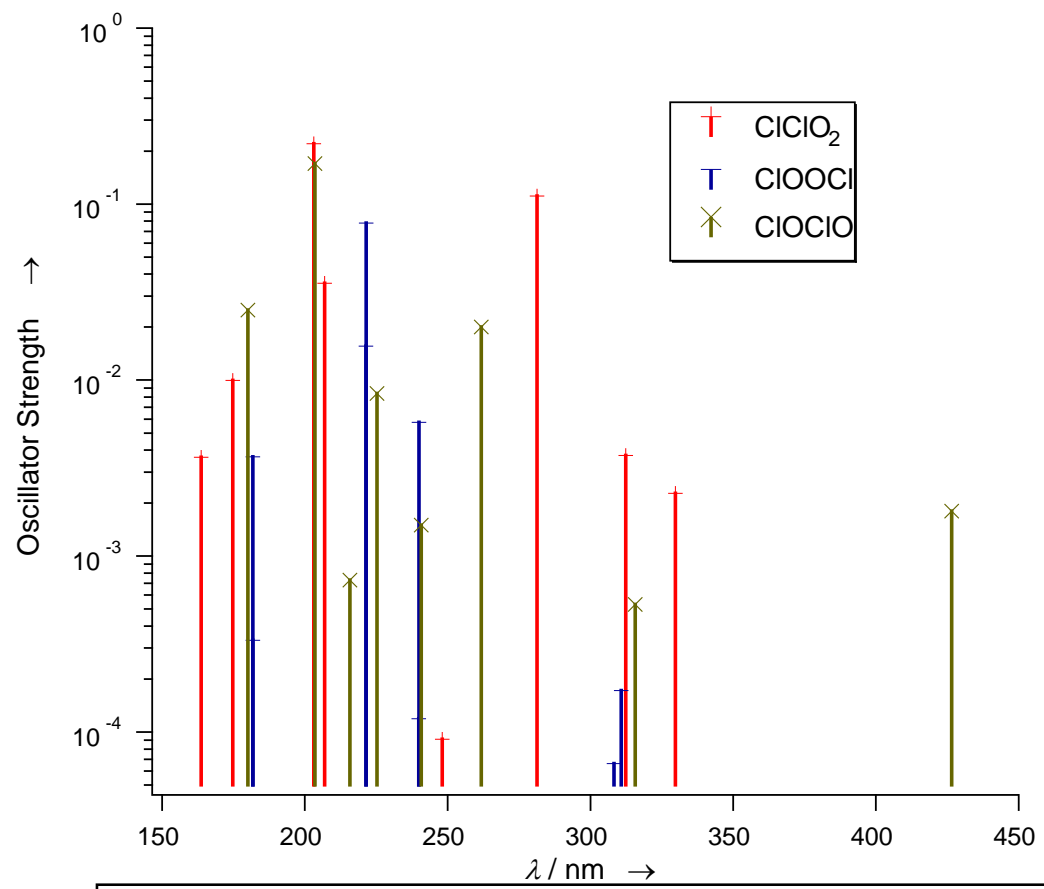

Figure 4. EOM-CCSD/aug-cc-pV(T+d)Z singlet excitation spectrum of $\mathrm{ClClO}_{2}, \mathrm{ClOOCl}$, and $\mathrm{ClOClO}$

M. T. Nguyen, K. A. Peterson, J. S. Francisco, and D. A. Dixon, J. Phys. Chem. A, 2008, 112, 9623-9627.

Sulfur clusters The discovery of a non-mass-dependent (NMD) signature in sulfur isotopes in Archean terrestrial rocks suggests that poly-sulfur species may have been prominent in the ancient Earth's atmosphere when $\mathrm{O}_{2}$ concentrations were low. In order to model the Archean sulfur cycle from sulfur isotope records, tetrasulfur, $\mathrm{S}_{4}$, is proposed to be a key species that is involved in many of the reactions as well as in the formation of sulfur aerosols in the early atmosphere. Pyrite formed from elemental sulfur is found to inherit an isotope signature that provides information about the sulfur composition of the early atmosphere, and, in particular, its $\mathrm{S}_{8}$ abundance. The $\mathrm{S}_{4}$ potential energy surface is essential to understanding the non-massdependent (NMD) signature in Archean terrestrial rock. An important feature of this potential energy surface is the possibility for sulfur atom isotope exchange mediated by the reaction of the excited $S\left({ }^{1} D\right)$ atom with $S_{3}$. Tetrasulfur, $S_{4}$, like $S_{8}$ may have a number of stable allotropes.

We have previously carried out CCSD(T) calculations on $\mathrm{S}_{2}$ and $\mathrm{S}_{3}$ extrapolated to the complete basis set limit. In the current study, we expand on the previous work to predict the geometry and frequencies of $\mathrm{S}_{4}$ with larger basis sets at the $\operatorname{CCSD}(\mathrm{T})$ level, as well as at the multi-reference 
configuration interaction level. $\mathrm{S}_{4}$ is an interesting compound with an open structure with $\mathrm{C}_{2 \mathrm{v}}$ symmetry. The molecule is trapezoidal with two short S-S bonds and a long S-S bond. The short $\mathrm{S}-\mathrm{S}$ bonds are comparable to the bond distance in $\mathrm{S}_{2}$. The geometry for the lowest energy $C_{2 v}$ structure of $\mathrm{S}_{4}$ shows good agreement with the recent microwave structure for $\mathrm{S}_{4}$. There is a low-lying $\mathrm{D}_{2 \mathrm{~h}}$ transition state at $1.6 \mathrm{kcal} / \mathrm{mol}$ above the $\mathrm{C}_{2 \mathrm{v}}$ ground state, which leads to interchange of the long S$\mathrm{S}$ bond between the two ends of the molecule. There is a low-lying triplet state $\left({ }^{3} \mathrm{~B}_{1 \mathrm{u}}\right)$ for $\mathrm{S}_{4}$ in $\mathrm{D}_{2 \mathrm{~h}}$ symmetry which is $10.8 \mathrm{kcal} / \mathrm{mol}$ above the $\mathrm{C}_{2 \mathrm{v}}$ singlet ground state. The S-S bond dissociation energy for $\mathrm{S}_{4}$ into two $\mathrm{S}_{2}\left({ }^{3} \Sigma_{\mathrm{g}}{ }^{-}\right)$ molecules is predicted to be $22.8 \mathrm{kcal} \mathrm{mol}^{-1}$. The

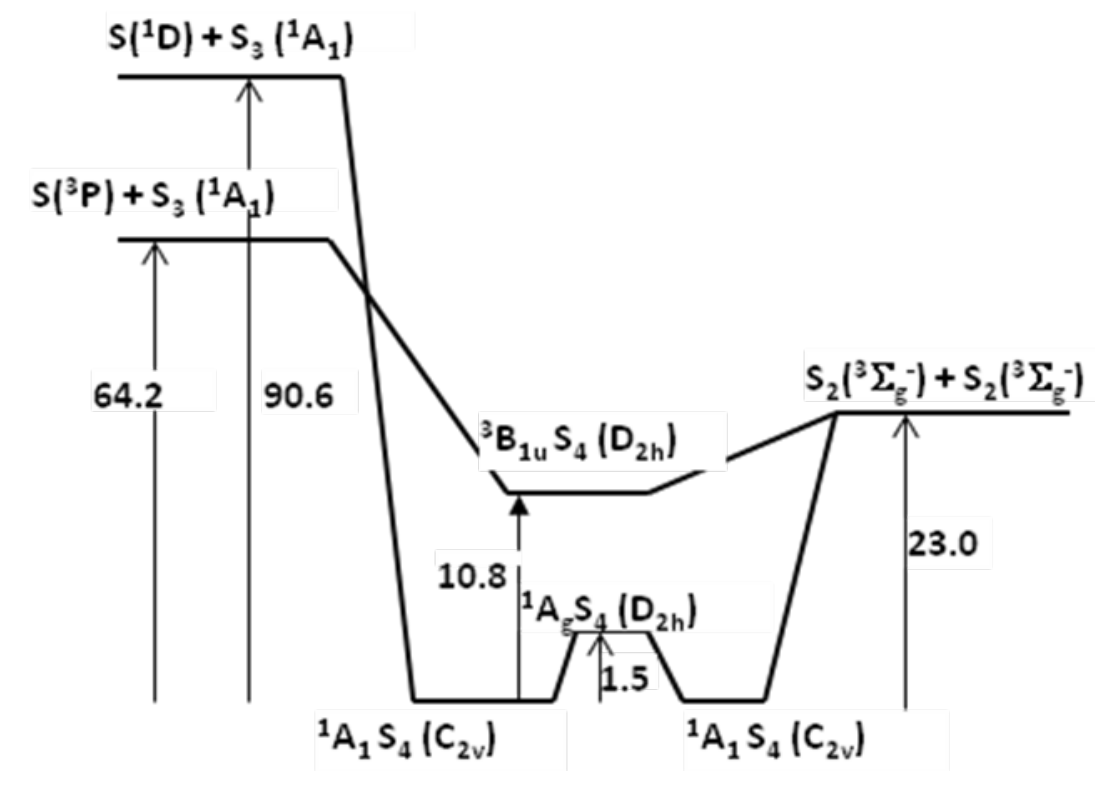
$\mathrm{S}-\mathrm{S}$ bond energy to yield $\mathrm{S}_{3}+\mathrm{S}\left({ }^{3} \mathrm{P}\right)$ is predicted to be $64 \mathrm{kcal} / \mathrm{mol}$. Figure 5 shows the thermodynamic relationships of $\mathrm{S}_{4}, \mathrm{~S}_{2}$, and $\mathrm{S}_{3}$. $\mathrm{S}_{3}$ can react with a ground state sulfur atom without spinorbit interactions to form $S_{4}$ in the ${ }^{3} B_{1 u}$ state. Photolysis of $S_{3}$ at wavelengths shorter than 260 $\mathrm{nm}$ has been suggested to yield $\mathrm{S}\left({ }^{1} \mathrm{D}\right)$ atoms so we need to include this process. $\mathrm{S}\left({ }^{1} \mathrm{D}\right)$ is 9239.0 $\mathrm{cm}^{-1}(26.4 \mathrm{kcal} / \mathrm{mol})$ above the ground ${ }^{3} \mathrm{P}$ state. The reaction of $\mathrm{S}\left({ }^{1} \mathrm{D}\right)$ with $\mathrm{S}_{3}$ leads to ground state $\mathrm{S}_{4}$. Both ground state singlet and excited state triplet $\mathrm{S}_{4}$ can dissociate endothermically to form two $S_{2}$ molecules in the ${ }^{3} \Sigma_{\mathrm{g}}$ - ground state. Because the barrier on the ground state singlet surface is so low, the molecule can easily access the $D_{2 h}$ geometry which enables it to readily switch the location of the long S-S bond and the location of the end atoms. $\mathrm{S}_{4}$ can then dissociate back to $\mathrm{S}+\mathrm{S}_{3}$ if the initial energy released on addition of $\mathrm{S}$ to $\mathrm{S}_{3}$ is not readily lost due to collision or radiative processes. Thus as shown below, isotope scrambling can readily occur in the formation of $\mathrm{S}_{3}$.

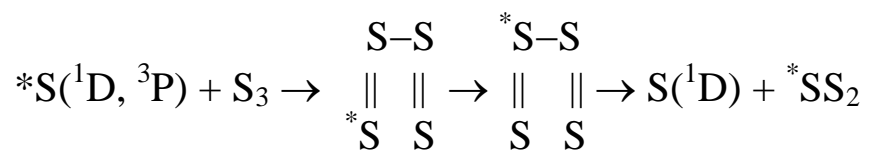

The formation of $S_{2}$, which is a less endothermic channel than re-forming reactants, could also lead to scrambling. Preferential isotope fractionation will of course be dependent on the dynamics of the process, especially those leading from smaller sulfur precursors to the formation of $S_{8}$. Our results suggest that the reaction between $S$ atoms and $S_{3}$ should lead to rapid isotopic exchange through $\mathrm{S}_{4}$ as an intermediate. This reaction should play an important role in sulfur isotope fractionations in elemental sulfur. This work was published in "Coupled-Cluster Study of 
the Electronic Structure and Energetics of Tetrasulfur, $\mathrm{S}_{4}$," M. H. Matus, D. A. Dixon, K. A. Peterson, J. A. W. Harkless, J. S. Francisco, J. Chem. Phys. 2007, 127, 174305 (7 pages).

Phosphorus nitrogen oxides The recent discovery of phosphorus containing molecules in the circumstellar and dense interstellar clouds has stimulated great interest in the astronomical characterization of phosphorus and nitrogen species in these clouds. The gas-phase chemistry in circumstellar shells rich in oxygen suggests that reactions with PN could lead to the formation of PNO or its isomers. However, there has been little work performed on molecules containing phosphorus, nitrogen, and oxygen including the molecules PNO, NOP, and NPO to aid in their spectroscopic identification in the interstellar medium. High level $a b$ initio electronic structure calculations using the coupled cluster $\operatorname{CCSD}(\mathrm{T})$ method with augmented correlation-consistent basis sets extrapolated to the complete basis set limit have been performed on PNO, NOP and NPO isomers and their corresponding anions and cations. The heats of formation are given in Table 2 together with the ionization potentials and electron affinities. This work was published in "Structure and Heats of Formation of the PNO, NOP, and PON Molecules and Their Anions and Cations,” D. J. Grant, D. A. Dixon, and J. S. Francisco, J. Chem. Phys., 2008, 128, 164305 (9 pages).

Table 2. Calculated heats of formation ( $\mathrm{kcal} / \mathrm{mol})$, ionization potentials $(\mathrm{eV})$, and electron affinities $(\mathrm{eV})$ at $298 \mathrm{~K}$. The values in parentheses include the CBS(Core-Valence) and Douglass-Kroll-Hess relativistic corrections

\begin{tabular}{lccc}
\hline Molecule & $\boldsymbol{\Delta} \mathbf{H}_{\mathbf{f}}$ & IP & EA \\
\hline $\operatorname{PNO}^{+}\left(C_{\infty v}\right)$ & $23.7(24.1)$ & 10.27 & 0.24 \\
$\operatorname{PNO}^{+}\left(C_{\infty}\right)$ & 260.6 & & \\
$\operatorname{PNO}^{-}\left(C_{s}\right)$ & 18.1 & & \\
$\operatorname{NOP}^{+}\left(C_{s}\right)$ & 52.0 & 9.89 & 0.82 \\
$\operatorname{NOP}^{+}\left(C_{s}\right)$ & 280.2 & & \\
$\operatorname{NOP}^{-}\left(C_{s}\right)$ & 33.0 & & \\
$\operatorname{NPO}^{+}\left(C_{\infty v}\right)$ & $22.3(22.6)$ & 12.06 & 2.36 \\
$\operatorname{NPO}^{+}\left(C_{\infty v}\right)$ & 300.4 & & \\
$\operatorname{NPO}^{-}\left(C_{s}\right)$ & -31.9 & & \\
$\operatorname{PO}^{2}(\Pi)$ & -7.1 & &
\end{tabular}

\section{Publications}

"Coupled-Cluster Study of the Electronic Structure and Energetics of Tetrasulfur, S," M. H. Matus, D. A. Dixon, K. A. Peterson, J. A. W. Harkless, J. S. Francisco, J. Chem. Phys. 2007, 127, 174305 (7 pages).

"Quantum-Chemical Calculations of Carbon-Isotope Fractionation in $\mathrm{CO}_{2}$ (g), Aqueous Carbonate Species, and Carbonate Minerals,” J. R. Rustad, S. L. Nelmes, V. E. Jackson, and D. A. Dixon, J. Phys. Chem. A, 2008, 112, 542-555.

"Mechanism of the Hydration of Carbon Dioxide: Direct Participation of $\mathrm{H}_{2} \mathrm{O}$ versus Microsolvation,” M. T. Nguyen, M. H. Matus, V. E. Jackson,V. T. Ngan, J. R. Rustad, and D. A. Dixon, J. Phys. Chem. A, 2008, 112, 10386-10398. 
"Structure and Heats of Formation of the PNO, NOP, and PON Molecules and Their Anions and Cations,” D. J. Grant, D. A. Dixon, and J. S. Francisco, J. Chem. Phys., 2008, 128, 164305 (9 pages).

"Prediction of Iron-Isotope Fractionation Between Hematite $\left(\alpha-\mathrm{Fe}_{2} \mathrm{O}_{3}\right)$ and Ferric and Ferrous Iron in Aqueous Solution from Density Functional Theory," J.R. Rustad and D.A. Dixon, J. Phys. Chem. A, 2009, 113, 12249-12255.

"Calculation of Boron-Isotope Fractionation between $\mathrm{B}(\mathrm{OH})_{3}(\mathrm{aq})$ and $\mathrm{B}(\mathrm{OH})_{4}{ }^{-}(\mathrm{aq})$ )" J. R. Rustad, E. J. Bylaska, V. E. Jackson and D. A. Dixon Geochimica et Cosmochimica Acta, 2010, 74, 2843-2850.

“Isotopic Fractionation of $\mathrm{Mg}^{2+}(\mathrm{aq}), \mathrm{Ca}^{2+}(\mathrm{aq})$, and $\mathrm{Fe}^{2+}(\mathrm{aq})$ with Carbonate Minerals,” J. R. Rustad, W. H. Casey, Q.-Z. Yin, E. J. Bylaska, A. R. Felmy, S. A. Bogatko V. E. Jackson and D. A. Dixon, Geochimica et Cosmochimica Acta, 2010, 74, 6301-6323.

\section{Presentations}

$20^{\text {th }}$ Coulson Lecture, "Computational Advances in Predicting the Behavior of Inorganic Compounds,” Department of Chemistry, The University of Georgia, Athens GA, April, 2007.

Plenary Lecture, “Computational Advances in Predicting Molecular Properties for Alternative Energy Solutions Computational Needs for Alternative and Renewable Energy,” Workshop (DOE OASCR) Rockville MD, Sept. 2007.

Invited lecture, “Computational Advances in Predicting the Behavior of Inorganic Compounds," Chemistry Department, University of North Texas, Feb 2008.

Invited lecture, "Computational Advances in Predicting the Behavior of Inorganic Compounds," Chemistry Department, University of South Alabama, Feb, 2008.

Plenary lecturer, "Computational Advances in Predicting Molecular Properties for Alternative Energy Solutions," 40 ${ }^{\text {th }}$ Annual Southeastern Regional American Chemical Society Undergraduate Research Conference, Mississippi, College, Clinton, MS, April 2008.

Talk, "ClClO 2 Is the Most Stable Isomer of $\mathrm{Cl}_{2} \mathrm{O}_{2}$. Accurate Coupled Cluster Energetics and Electronic Spectra of $\mathrm{Cl}_{2} \mathrm{O}_{2}$ Isomers," SPARC workshop on the Role of Halogen Chemistry in Polar Stratospheric Ozone Depletion, Cambridge U, Cambridge, UK, June, 2008.

Invited Lecture, "Accurate predictions of the thermodynamic properties of the halogen oxides including the XYO2 isomers for X and $\mathrm{Y}=\mathrm{Cl}, \mathrm{Br}$, and I," Atmospheric Chemistry Symposium, Division of Analytical Chemistry, American Chemical Society Spring National Meeting, Salt Lake City, March 2009. 
Invited Lecture, "Prediction of Reliable Heats of Formation and Bond Dissociation Energies," 49th Sanibel Symposium, St. Simons Island, Feb. 2009.

Invited Lecture, "Computational chemistry for catalysis, hydrogen storage, and the stratosphere," Mississippi State University, March 2009.

Lecture and co-Organizer, "Computational Geochemistry: Predicting Properties of the MineralWater Interface,” DOE BES Earth Sciences Council workshop: Computational Geochemistry: Predicting Properties of the Mineral-Water Interface, Annapolis, MD, Jan. 2010.

Invited Lecture, "Applications of electronic structure theory for computational geochemistry: Aiming for the petaflop," ACS National Meeting, Division of Geochemistry Symposium: Predicting Molecular Properties at the Mineral-Water Interface: Challenges and Opportunities for High Performance Computing, San Francisco, March, 2010.

Invited Lecture, "Computational Chemistry: Applications to Catalysis and Environmental Science,” Chemistry, Washington State University, March, 2010.

Invited Lecture, "Prediction of thermochemical properties: Applications to atmospheric chemistry, catalysis, and alternative energy, Physical Chemistry seminar, Georgia Institute of Technology, Sept. 2010. 